\title{
Vertical integration and non-linear price adjustments: the Spanish poultry sector
}

\author{
Monia Ben-Kaabia \\ Department of Economic Analysis \\ University of Zaragoza (Spain) \\ José M. Gil and Mehrez Ameur \\ CREDA-UPC-IRTA \\ Department of Agrofood Engineering and Biotechnology. \\ Polytechnic University of Catalonia \\ Barcelona (Spain)
}

\begin{abstract}
The analysis of asymmetries in the price transmission mechanism at different levels of the marketing chain provides a good indicator of market efficiency in vertically related markets. The objective of this paper is to investigate the non-linear adjustments of prices in the poultry marketing chain in Spain. The methodology used is based on the multivariate approach to specify and estimate a Threshold Autoregressive Model. Price relationships at feed industry, producer and retail levels are considered. Results indicate that, in the long run, price transmission is perfect and any supply or demand shocks are fully transmitted to all prices in the system. In the short run, price adjustments between the feed and the farmer levels are fairly symmetric and are representative of a cost-push transmission mechanism. On the other hand, retailers benefit from any shock, whether positive or negative, that affects supply or demand conditions when price spreads are increasing, while price behaviour is closely related to competitive markets when faced with declining price spreads.
\end{abstract}

EconLit classification: C320, Q130 


\section{Introduction}

Vertical integration is becoming one of the most important structural characteristics of agricultural markets. Economic theory suggests three main motivations for tighter vertical coordination linkages (Lawerence et al., 1997): risk reduction, market imperfections, and the implementation of non-competitive strategies (barriers to entry, price discrimination, etc.). However, no consensus exists about the effects on social welfare. While limiting the access of competitors to input sources and product outlets is viewed as an adverse consequence, gains in efficiency may be achieved that offset those negative effects.

Something similar happens when analysing the consequences of vertical integration on price transmission, which has been one of the main research interests among agricultural economists, given that such relationships are a good indicator of market efficiency. Some authors suggest that vertical coordination contributes to a rapid adjustment, according to short-run goals. Thus, cost increases are immediately transferred to the final output price. Others think that, in these markets, firms fix longrun goals. Therefore, the adjustment process takes longer.

In any case, there is a common feeling that retail prices do not react very quickly to changes in market conditions (Borenstein et al., 1997; Peltzman, 2000). In this situation the retail price will not be equal to the marketing clearing price and, therefore, will generate an excess supply. Consequently, consumers will not benefit from declining farm prices which suggests a redistribution of consumer welfare.

Potential explanations for these asymmetric price relationships are market power at the retail level ${ }^{1}$ (Boyd and Brorsen, 1988; Bailey and Brorsen, 1989; Griffith and Piggott, 1994; Borestein et al.,1997; and Bettendorf and Verboven, 2000; among others), adjustment costs (Blinder et al., 1998; Buckle and Carlson, 2000; and Chavas and Mehta, 2002), differences in cost shares and input substitution possibilities (Bettendorf and Verboven, 2000), inventory holding (Reagan and Witzman, 1982);

\footnotetext{
1 Although asymmetries have been linked to non-competitive behaviour, this is not necessarily true. McCorriston et al. (2001), with formal grounding in rational firm conduct, showed that in presence of market power price changes could be greater or less than the competitive benchmark case depending on the interaction between such market power and returns to scale. In a similar way, although using an alternative theoretical approach, Azzam (1999) showed that, in a context of two-period model of spatially competitive retailers, asymmetries will be generated provided that spatially competitors face concave spatial demand functions.
} 
asymmetric information (Bailey and Brorsen (1989), and public intervention (Kinnucan and Forker, 1987). In any case, as there are many possible reasons why price relationships along the food chain may be asymmetric, before explanations can be given for specific markets, the first step is to analyse the existence of such asymmetric price adjustments.

In this paper we investigate the price transmission mechanism in the Spanish poultry marketing chain. Particularly, we will focus our study on answering the question of whether Spanish poultry farmers benefit or not from unanticipated positive and negative supply or demand shocks. Poultry has been one of the agricultural sectors where vertical coordination practices have developed earlier and more intensively. The high dependence of poultry production on feed has led to different kinds of coordination between the different stages of meat production, ranging from contracts to vertical integration. Nowadays, almost $95 \%$ of the poultry production in Spain is carried out under some type of vertical integration or coordination, and so it is a good example for analysing price behaviour in vertically related markets.

The rest of the paper is organised as follows. In Section 2 the main characteristics of the Spanish poultry sector are described. Section 3 provides a description of the methodological approach used in the paper. Section 4 reports our empirical results. Finally, Section 5 closes the paper with some concluding remarks.

\section{Relevant features of the Spanish poultry sector}

The poultry sector in Spain accounts for 5\% of the Final Agricultural Output, $20 \%$ of the total meat production and $14 \%$ of the total European Union (EU) poultry production. Furthermore, it is the second main supplier for the meat processing industry after pork. Together, these constitute the most important components of the Spanish agro-food industry in terms of production and employment. In 2000, it accounted for $20 \%$ of the total agro-food industry output.

Poultry is also a key agricultural sector because of its close links with the grain and feed sectors. In contrast to the Northern European countries, and in spite of its decreasing use, cereal still constitutes the main raw material in feed composition. This can be explained by the distance to the most important harbours in Europe, through 
which cereal substitute products are imported, and by the existing surpluses in cereal production (mainly barley).

The animal feed industry is the third most relevant component in the Spanish agro-food industry, representing around $10 \%$ of the total output. Moreover, $25 \%$ of the quantity produced is destined to the poultry sector. However, only $5 \%$ of the poultryfeed production is marketed in a "free market". In other words, 95\% of feed is destined to the "cautive" market, constituted by poultry farms, which are linked to the feed industry through some kind of vertical coordination.

Poultry and pork have been two of the agricultural sectors where vertical coordination practices have developed earlier and more intensively. The high dependence of poultry production on feed has led to different kinds of coordination between both stages of meat production, ranging from contracts to vertical integration. Thus both benefit from a risk reduction. Nowadays, vertical arrangements have spread to the meat industry and, in some cases, to the retail sector.

Taking into account the objective of this paper, the most relevant information is provided by the evolution of different prices in the Spanish poultry chain. Figure 1 shows the evolution of monthly feed (FP), producer (PP) and retail (RP) price indexes $(1980=100)$ during the period 1980-2001. Feed and producer prices are taken directly from publications of the Spanish Ministry of Agriculture, Food and Fisheries (MAPA). Retail prices are taken from the Boletín Económico del ICE (Ministry of Finance).

(Insert Figure 1 about here)

As can be observed, the three prices show a similar pattern during the whole period although more volatility is observed after Spain's joining the EU, mainly at producer and retail levels. Marketing margins at the retail level have increased during the last decade. Furthermore, it is important to note that the retail price tends to react slightly later than the other two prices when facing changing market conditions.

\section{Methodology}

Using somevariations of a model first developed by Wolframm (1971) and later modified by Houck (1977), most authors have found evidence of both asymmetries in 
price adjustments and a cost-push price transmission mechanism for different products ${ }^{2}$ (see, for instance, Ward, 1982; Kinnucan and Forker, 1987; Hahn, 1990; and Hansmire and Willett, 1992; Griffith and Piggott, 1994; among others). More recently, Pelztman (2000), in an exhaustive paper, found that retail prices tended to rise faster than they fell suggesting a revision of the traditional economic theory of markets.

However ${ }_{2}$ results from the empirical models utilised by the above authors to investigate asymmetriese in price transmission have to be interpreted with caution, as they have not adequately consideredt the time series properties of the data. Von Cramon-Taubadel (1998) showed that the traditional econometric specification used to test for asymmetric price transmission is inconsistent with cointegration. He proposed an alternative specification of the Wolffram-Houck model based on the error correction representation and taking into account the procedure approach suggested by Granger and Lee (1989).

A second limitation is that, generally, it is assumed that the underlying price transmission mechanism is linear. However, the presence of fixed costs of adjustment in the food chain may generate non-linear reactions, that is to say, price adjustments may be different depending both on the magnitude and the sign of the initial shock. In other words, it is not unrealistic to suppose that only when the initial shock surpasses the critical threshold do economic agents react to it. If this is the case, then threshold models of dynamic economic equilibrium are more appropriate when analysing dynamic price relationships between markets in the food chain.

In this paper, we apply the methodological approach suggested by Hansen and Seo (2001), which has already been applied for spatially separated markets by Goodwin and Piggott (2001) and Lo and Zivot (2001). More precisely, we have initially specified a three-regime Threshold Vector Autoregression model $\left(\mathrm{TVECM}_{3}\right)$ to analyse the price transmission mechanism in the Spanish poultry sector.

\subsection{Threshold cointegration}

Let $\mathrm{P}_{\mathrm{t}}=\left(\mathrm{P}_{1 \mathrm{t}}, \mathrm{P}_{2 \mathrm{t}}\right)$ ' be the $\log$ price of a good at two different levels of the marketing channel, assuming that $\mathrm{P}_{\mathrm{t}}$ is a vector of $\mathrm{I}(1)$ time series which is cointegrated

\footnotetext{
2 The only exception is Boyd and Brorsen (1988), who do not find asymmetric price relationships in the US pork sector.
} 
with a common cointegrating vector $\beta^{\prime}=\left(1,-\beta_{2}\right)$. The linear VECM representation of order $k$ of $\mathrm{P}_{\mathrm{t}}$ can be written as:

$$
\Delta \mathrm{P}_{\mathrm{t}}=\alpha\left[\omega_{\mathrm{t}-1}(\beta)\right]+\sum_{\mathrm{i}=1}^{\mathrm{k}-1} \Gamma_{\mathrm{i}} \Delta \mathrm{P}_{\mathrm{t}-\mathrm{i}}+\varepsilon_{\mathrm{t}}
$$

where $\omega_{t}(\beta)=\beta^{\prime} P_{t-1}$ is the cointegrating vector evaluated at the generic value $\beta=(1,-$ $\left.\beta_{2}\right)^{\prime} ; \Gamma_{\mathrm{i}}, \mathrm{i}=1,2 \ldots$ are $(2 \times 2)$ matrices of short-run parameters; $\alpha$ is a $(2 \times 2)$ matrix; and $\varepsilon_{\mathrm{t}}$ is a vector of error terms that are assumed to be independently and identically Gaussian distributed with a covariance matrix $\Sigma$ which is assumed to be positive definite. $\beta$ is the cointegrating vector which is commonly interpreted as the long-run equilibrium relation between the two prices in $\mathrm{P}_{\mathrm{t}}$, while $\alpha$ gives the weights of the cointegration relationship in the VECM equations.

Following Lo and Zivot (2001), a three-regime threshold Vector Error Correction Model ( $\left.\mathrm{TVECM}_{3}\right)$, can be written as:

$$
\Delta \mathrm{P}_{\mathrm{t}}=\left\{\begin{array}{lll}
\mu^{1}+\alpha^{1} \omega_{\mathrm{t}-1}(\beta)+\sum_{\mathrm{i}=1}^{\mathrm{k}-1} \Gamma_{\mathrm{i}}^{1} \Delta \mathrm{P}_{\mathrm{t}-\mathrm{i}}+\varepsilon_{\mathrm{t}}^{1}, & \text { if } \quad \omega_{\mathrm{t}-1}(\beta)<\lambda^{2} \\
\mu^{2}+\alpha^{2} \omega_{\mathrm{t}-1}(\beta)+\sum_{\mathrm{i}=1}^{\mathrm{k}-1} \Gamma_{\mathrm{i}}^{2} \Delta \mathrm{P}_{\mathrm{t}-\mathrm{i}}+\varepsilon_{\mathrm{t}}^{2}, & \text { if } \quad \lambda^{1} \leq \omega_{\mathrm{t}-1}(\beta) \leq \lambda^{2} \\
\mu^{3}+\alpha^{3} \omega_{\mathrm{t}-1}(\beta)+\sum_{\mathrm{i}=1}^{\mathrm{k}-1} \Gamma_{\mathrm{i}}^{3} \Delta \mathrm{P}_{\mathrm{t}-\mathrm{i}}+\varepsilon_{\mathrm{t}}^{3}, & \text { if } \quad \omega_{\mathrm{t}-1}(\beta)<\lambda^{1}
\end{array}\right.
$$

where $\lambda=\left(\left(\begin{array}{ll}\lambda_{1} & \lambda_{2}\end{array}\right)\right.$ are the threshold parameters that delineate the different regimes.

As can be observed, the TVECM 3 in (2) specifies that the adjustment towards the long-run equilibrium relationship $\left[\omega_{t}(\beta)=\beta^{\prime} P_{t-1}\right]$ is regime-specific. This model says that the dynamic adjustment of $P_{i t}$ depends on the magnitude of $\omega_{t}(\beta)=\beta^{\prime} P_{t-1}$.

A special case of the TVECM given in (2) occurs if price changes are smaller than transaction costs. In this case, prices will not adjust in the second regime (in the middle one) implying that prices are not cointegreted, that is, $\alpha^{2}=0$ and $\mu^{2}=0$. The resulting model is the so-called Band-TVECM. If $\omega_{t}(\beta)=\beta^{\prime} P_{t-1}$ is within the band, then prices are not cointegrated and $\mathrm{P}_{\mathrm{t}}$ follows a $\operatorname{VAR}(\mathrm{k})$ without a drift. However, in the outer bands economic forces push prices moving together implying cointegration with different adjustment coefficients. If $\omega_{t}(\beta)>\lambda^{2}\left(\omega_{t}(\beta)<\lambda^{1}\right)$, then the cointegrating 
vector reverts to the regime-specific mean with an adjustment coefficient ${ }^{3} \rho^{3}\left(\rho^{1}\right)$ while $\Delta \mathrm{P}_{\mathrm{t}}$ adjusts to the long-run equilibrium with a speed of adjustment vector $\alpha^{3}\left(\alpha^{1}\right)$.

Note that when the threshold parameters $\left(\lambda^{1}\right.$ and $\left.\lambda^{2}\right)$ are both fixed (known a priori), the model is linear in the remaining parameters. In such circumstances, and under the assumption that errors $\varepsilon_{\mathrm{t}}$ are iid gaussian, parameters in model (2) can be estimated by multivariate least squares. However, in general, the threshold parameters ( $\lambda^{\mathrm{i}}$, s) are unknown and need to be estimated along with the remaining parameters of the model. Lo and Zivot (2001) propose a strategy which combines Hansen's (1999) approach to estimate two- and three-regime univariate TAR models and Tsay's (1998) procedure to estimate multivariate TVECM.

In the first step, the threshold parameters can be estimated through the following optimisation program ${ }^{4}$ :

$$
\left(\lambda^{1}, \lambda^{2}\right)=\arg \min _{\lambda \in\left[\lambda_{L}, \lambda_{U}\right]}\left(S_{3}\left(\lambda^{1}, \lambda^{2}\right)\right)
$$

where

$$
S_{3}\left(\lambda^{1}, \lambda^{2}\right)=\ln \left|\hat{\Sigma}\left(\lambda^{1}, \lambda^{2}\right)\right|
$$

and $\hat{\Sigma}(\beta, \lambda)$ is the estimated covariance matrix of model (2) conditional on $(\lambda)$.

The second step consists of testing if the dynamic behaviour and the adjustment towards the long-run equilibrium relationship is linear or exhibits threshold nonlinearity using the sup-LR statistic proposed by Lo and Zivot (2001):

$$
L R_{13}=T\left(\ln |\hat{\Sigma}|-\ln \left|\hat{\Sigma}\left(\lambda_{1}, \lambda_{2}\right)\right|\right)
$$

where $\hat{\Sigma}$ and $\hat{\Sigma}\left(\lambda_{1}, \lambda_{2}\right)$ are the residual covariance matrices of the VECM and TVECM, respectively.

${ }^{3}$ The adjustment coefficient is obtained as follows:

$$
\rho^{\mathrm{j}}=1+\beta^{\prime} \alpha^{\mathrm{j}}=1+\left[\begin{array}{ll}
1 & -\beta_{2}
\end{array}\right]\left[\begin{array}{l}
\alpha_{1}^{\mathrm{j}} \\
\alpha_{2}^{\mathrm{j}}
\end{array}\right]=1+\alpha_{1}^{\mathrm{j}}-\beta_{2} \alpha_{2}^{\mathrm{j}}
$$

\footnotetext{
${ }^{4}$ The grid search minimizes the log determinant of the residual covariance matrix of the TVECM, which is analogous to maximizing a standard LR test. This criterion differs from the approach used in other empirical analyses (Goodwin and Holt, 1999 and Goodwin and Piggott, 20001) in that it does not assume crossequation independence between the residuals.
} 
Once non cointegration and linearity have been rejected, there are several questions that have to be answered in the empirical analysis before allowing the researcher to interpret results. The most important, without doubt, is to determine which kind of threshold model is more appropriate for the data (number of regimes, the TVECM or the Band-TVECM, and a symmetric or asymmetric threshold model). This issue will be properly addressed in the empirical analysis.

\subsection{Non-linear impulse response functions}

Once the TVECM has been estimated, it is useful to analyse the short-run dynamic behaviour of the variables by computing the impulse response functions. This can be particularly suitable for studying the time path response of variables to unexpected shocks at time t. However, given that the non-linear time series model does not have a Wald representation, computing the IRF for these types of models is not an easy task. In addition, as discussed in Koop et al. (1996), the complications arise because in non-linear models ${ }^{5}:$ i) the effect of a shock depends on the history of the time series up to the point where the shock occurs; and ii) the effect of a shock depends on the sign and the size of the shock. As a consequence, in non-linear models impulse response functions depend on the combined magnitude of the history $\mathrm{P}_{\mathrm{t}-1}=\omega_{\mathrm{t}-1}$ and the magnitude of the shock $\delta$ (relative to the threshold value $\lambda$ )

The Generalised Impulse Response Functions (GIRF) introduced by Koop et al. (1996) and Potter (1995) offer a useful generalisation of the concept of impulse responses to non-linear models. Their analysis focused on the asymmetric response of the variables to one standard deviation of both positive and negative shocks. The Nonlinear Impulse Response Functions (NIRF) are defined in a similar manner to traditional GIRF, except for replacing the standard linear predictor by a conditional expectation. Hence, the NIRF for a specific shock $\varepsilon_{t}=\delta$ and history $\mathrm{P}_{\mathrm{t}-1}=\varphi_{\mathrm{t}-1}$ (the history of the system) is defined as:

$$
\begin{aligned}
\operatorname{NIRF}\left(\mathrm{n}, \delta, \varphi_{\mathrm{t}-1}\right)= & \mathrm{E}\left[\mathrm{P}_{\mathrm{t}+\mathrm{n}} \mid \varepsilon_{\mathrm{t}}=\delta, \varepsilon_{\mathrm{t}+1}=\ldots=\varepsilon_{\mathrm{t}+\mathrm{n}}=0, \varphi_{\mathrm{t}-1}\right] \\
& -\mathrm{E}\left[\mathrm{P}_{\mathrm{t}+\mathrm{n}} \mid \varepsilon_{\mathrm{t}}=0, \varepsilon_{\mathrm{t}+1}=\ldots=\varepsilon_{\mathrm{t}+\mathrm{n}}=0, \varphi_{\mathrm{t}-1}\right] \text { for } \mathrm{n}=0,1, \ldots \mathrm{N}
\end{aligned}
$$

Taking into account this definition, it is clear that the NIRF is a function of $\delta \in \varepsilon_{\mathrm{t}}$ and $\varphi_{\mathrm{t}-1} \in \Omega_{\mathrm{t}-1}\left(\Omega_{\mathrm{t}-1}\right.$ is the history or information set at $\mathrm{t}-1$ used to forecast future values

\footnotetext{
5 In the linear model, IRF are symmetric, in the sense that a shock of size $-\delta$ has exactly the opposite effect to that of a shock of size $\delta$.
} 
of Pt). Given that $\delta$ and $\varphi_{\mathrm{t}-1}$ are realisations of the random variables $\Omega_{\mathrm{t}-1}$ and $\varepsilon_{\mathrm{t}}$, Koop et al. (1996) stress that NIRF themselves are realisations of random variables given by:

$$
\operatorname{NIRF}\left(\mathrm{n}, \varepsilon_{\mathrm{t}}, \Omega_{\mathrm{t}-1}\right)=\mathrm{E}\left[\mathrm{P}_{\mathrm{t}+\mathrm{n}} \mid \varepsilon_{\mathrm{t}}, \Omega_{\mathrm{t}-1}\right]-\mathrm{E}\left[\mathrm{P}_{\mathrm{t}+\mathrm{n}} \mid \Omega_{\mathrm{t}-1}\right]
$$

\section{Empirical analysis}

\subsection{Data and preliminary analysis}

In this section we perform the multivariate threshold cointegration approach described above to analyse the price transmission mechanism in the Spanish poultry sector. The methodological approach consists of the following steps. After testing for unit roots, we test for cointegration using the Johansen (1988) procedure. Second, taking into account the results from the previous step, several restrictions are imposed on the cointegrating vector in order to test for long-run price homogeneity. If cointegration is found, the next step consists of determining whether the dynamics of the data can be described by threshold-type non-linearities. Finally, if the price transmission mechanism follows a threshold error correction model (TVECM), then non-linear Generalised Impulse Response functions are calculated in order to analyse the response of each price to unanticipated positive and negative shocks.

The data used have been described in Section 2. All variables are expressed in natural logarithms. Before implementing the Johansen and Juselius' procedure for the cointegration analysis among the price series, we first examine their stochastic time series properties. Due to the monthly frequency of data, seasonality is investigated by implementing seasonal unit root tests following the procedure developed by Franses (1991). As can be observed in Table 1, results from the seasonal unit root tests clearly indicate that the three price series are stationary. Moreover, seasonal dummy variables were not significant indicating that neither a deterministic nor a stochastic seasonal component was present. Only the null of the unit root at the regular frequency $\left(\pi_{1}=0\right)$ cannot be rejected. However, the tests presented are not very powerful if seasonal components are not present and traditional unit root tests should be implemented.

(Insert Table 1 about here)

However, a second problem arises when examining Figure 1, as price series exhibit a changing trend around 1985-86, that is, when Spain joined the EU. In this 
case, the distribution of traditional statistics to test for unit roots change (Perron, 1989 and Rappoport and Reichlin, 1989) and auxiliary regressions must incorporate the structural change (Perron, 1989 and Banerjee et al., 1992). Unit root tests with structural breaks are conducted for each price series. Table 2 shows the main results. In the three price series the null of non- stationarity cannot be rejected indicating that all price series are $\mathrm{I}(1)$.

(Insert Table 2 about here)

\subsection{Cointegration analysis}

In this section we address the first step to specify a TVECM (i.e. testing for cointegration and estimating the cointegrating relationship). The Johansen procedure is used to test for cointegration among the time series. Escribano and Mira (1996) and van Dijk and Franses (1997) show that the cointegrating vector can still be estimated superconsistently in the presence of neglected non-linearity in the adjustment process. Nevertheless, given that the $\mathrm{TVECM}_{3}$ defined in (2) is bivariate with only one cointegrating vector, the analysis has been carried out considering two separate subsystems. The first one considers the relationship between the feed price (FP) and the producer price (PP), while the second analyses the relationship between the producer price (PP) and the retail price (RP).

However, the presentation of the data in the previous section has revealed that the single series may be characterized by a broken linear trend due to the Spain's integration into the EU. These deterministic components may affect log-price differences and have to be included in the price relationships in order to obtain stationarity. So, to test for cointegration we have used a generalization of the multivariate Johansen testing procedure proposed by Johansen et al. (2000), which allows for broken linear trend levels.

Assuming one break in the deterministic components (intercept and trend) at time $t=T_{1}$, Johansen's procedure is based on the definition of a $p$-dimensional VAR model of k-th order in the form of a vector error correction model (VECM) which, in matrix form, can be expressed as:

$\Delta_{t}=\alpha\left(\beta Z_{t-1}+\varphi_{1}(t-1) D_{1, t}+\varphi_{2}(t-1) D_{2, t}\right)+\sum_{i=1}^{k-1} \Gamma_{i} \Delta Z_{t-i}+\mu_{1} D_{1, t}+\mu_{2} D_{2, t}+\sum_{i=1}^{k} \delta_{i} D_{1, t-i}+\varepsilon_{t}(6)$ 
where $Z_{t}$ is the vector $(\mathrm{px} 1)$ of price series being considered, $\Delta \mathrm{Z}_{\mathrm{t}}=\mathrm{Z}_{\mathrm{t}}-\mathrm{Z}_{\mathrm{t}-1} ; \mathrm{D}_{1, \mathrm{t}}$ is a dummy variable which takes the value one for $\mathrm{t}<\mathrm{T}_{1}$ and zero otherwise, $\mathrm{D}_{2, t}=1-\mathrm{D}_{1} ; \Gamma_{\mathrm{i}}$ are matrices $(\mathrm{pxp})$ of short-run parameters $(\mathrm{i}=1, . ., \mathrm{k}-1) ; \phi_{1}, \phi_{2}, \mu_{1}$, and $\mu_{2}$ are $(\mathrm{px} 1)$ parameter vectors related to the linear trends and intercepts of the two regimes, and $\varepsilon_{\mathrm{t}} \sim \mathrm{N}(0, \Sigma)$.

The Johansen procedure tests the rank $r$ of the matrix $\Pi=\alpha \beta^{\prime}$, where $\beta$ is a matrix of long-run coefficients such that the $\left(\beta^{\prime} Z_{t-1}\right)$ term represents the $(r)$ cointegration relationships in the multivariate model which ensure that $Z_{t}$ converge to their long-run steady-state solutions, whilst the parameters of matrix $\alpha$ measure the speed of adjustment of the dependent variables to the long-run equilibria reflected in the term $\left(\beta^{\prime} Z_{t}\right)$. Hence, the rank $r$ determines the number of cointegration relationships between the p variables of the system (6). Johansen et al. (2000) proposed the trace statistic to test for the cointegration rank. Critical values for the asymptotic distribution of the test can be computed by using a response surface given in Johansen et al. (2000).

The optimum lag of the VECM has been selected on the basis of the Akaike Information Criterion (AIC) and the Likelihood Ratio test proposed by Tiao and Box (1981). Both tests provide consistent results and indicate that both systems have to include five lags. Misspecification tests for autocorrelation and normality, described in Doornik and Hendry (1997), have been carried out for each system to check for the statistical adequacy of the model. Results indicate that the models specified above are quite satisfactory.

Table 3 (first row) shows the results from the cointegration tests. At the 5\% level of significance, the trace statistic indicates that the null hypothesis of one cointegrating vector cannot be rejected in either system. Given that the cointegrating rank is one, we have tested whether the price transmission between feed and producer prices and between producer and retail prices is perfect in the long run. This hypothesis states that the cointegrating vector $\beta$ in each system should satisfy the long-run price homogeneity condition $(1,-1)$. All restriction tests on the cointegrating vector are asymptotically $\chi^{2}(\mathrm{v})$ distributed where, $\mathrm{v}$ is the number of imposed restrictions ${ }^{6}$. Results from the Likelihood Ratio (LR) statistic (second row of Table 3) show that the homogeneity restriction

\footnotetext{
${ }^{6}$ For further details, see Johansen and Juselius (1994) and Johansen (1995).
} 
cannot be rejected and has empirical support. Consequently, it can be concluded that, in the long run, any change in any of the prices at different levels of the Spanish poultry marketing chain is fully transmitted to the rest.

(Insert Table 3 about here)

As far as the significance of the deterministic components included in the model concerned, Table 3 (third and fourth rows) shows that in both systems the trend coefficients are not significant at the 5\% level of significance. As a consequence, linear trends can be completely excluded from the model, implying that intercepts can be restricted to the cointegrating space (as Table 3 shows, intercepts are significant). Finally, the restricted cointegrating vectors are given by (Table 3, fifth row):

$$
\begin{aligned}
& \mathrm{LnPP}-\operatorname{lnFP}=1.167 \mathrm{D}_{1 \mathrm{t}}+1.070 \mathrm{D}_{2 \mathrm{t}} \\
& \mathrm{LnRP}-\ln \mathrm{PP}=0.604 \mathrm{D}_{1 \mathrm{t}}+0.792 \mathrm{D}_{2 \mathrm{t}}
\end{aligned}
$$

The constant terms in (7) and (8) represent the price spread at the farm and retail levels, respectively. Taking into account that all prices are expressed in logarithms, (7) and (8) represent percentage spread models with a mark-up of $\left(e^{\alpha}-1\right)$ (with $\alpha$ being the constant) (Tiffin and Dawson, 2000). Hence, the farm and retail marketing margins can be expressed as follows:

$$
\begin{aligned}
& \text { Farm margin }=\left(e^{\alpha}-1\right) \times F P \times 100 \\
& \text { Retail margin }=\left(e^{\alpha}-1\right) \times W P \times 100
\end{aligned}
$$

The corresponding values of marketing margins for the two sub-periods in which the sample has been divided (before and after Spain joining the EU) are shown in last row of Table 3. The farm margin has decreased by $10 \%$ as a consequence of increasing costs after joining the EU and the stabilisation of farm prices. However, the retail margin, as shown in Figure 1, has increased by $50 \%$.

\subsection{Threshold cointegration}

Once the presence of a long-run equilibrium relationship between the two pairs of prices has been detected, the next question is whether possible non-linearities exist in the adjustment process. We start by testing non-linearity and, if the null of linearity is rejected, by determining the number of regimes in each of the two TVECM specified for systems (FP-PP) and (PP-RP), respectively, considering the estimated cointegrating vectors, given in (7) and (8), as the respective threshold variables $\left(\omega_{\mathrm{t}-1}\right)$. The LR test for 
linearity against a multivariate $\operatorname{TVECM}_{3}\left(\mathrm{LR}_{1,3}\right)$ is based on a VECM with 5 lags for systems (FP-PP) and (PP-RP), respectively. Results from $\mathrm{LR}_{1,3}$ linearity tests are shown in Table 4. In both systems, the null of linearity is rejected at the 5\% level, in favour of the threshold model.

(Insert Table 4 about here)

Given that linearity is rejected in favour of threshold non-linearity, next we test which threshold model is more appropriate to characterize the non-linear dynamic adjustments of prices using the following Likelihood Ratio (LR) statistic (Lo and Zivot, 2001):

$\left.L R_{2,3}=T\left(\ln \mid \hat{\Sigma}_{2}(\hat{\lambda})\right]-\ln \left[\hat{\Sigma}_{3}(\hat{\lambda})\right]\right)$

where $\hat{\Sigma}_{2}(\hat{\lambda})$ and $\hat{\Sigma}_{3}(\hat{\lambda})$ are the estimated residual covariance matrices from the unrestricted $\mathrm{TVECM}_{2}$ and $\mathrm{TVECM}_{3}$, respectively. The asymptotic distributions of $\mathrm{LR}_{2,3}$ are non-standard and bootstrap methods can be used to compute approximate p-values.

As can be observed from Table 4, in both cases the LR statistic rejects the null of a $\mathrm{TVECM}_{2}$ against the alternative of a three-regime $\mathrm{TVECM}_{3}$, suggesting that price transmission in the Spanish poultry marketing chain can be characterised by a threeregime threshold process. At the bottom of Table 4 the estimated threshold parameters from the $\mathrm{TVECM}_{3}$ are shown for both systems.

The estimated $\mathrm{TVECM}_{3}$ coefficients are shown in Table 5 along with results from the misspecification tests. As can be observed, the results of the diagnostic tests suggest that the estimated models in both systems are adequate as there is no evidence for remaining residual autocorrelation, $\mathrm{ARCH}$ tests fail to reject the null of homocedasticity and, finally, normality cannot be rejected. Moreover, for both systems, the estimated parameters in the outer regimes are significant and have the expected sign. However, in the middle regime (regime 2) adjustment coefficients are not significant.

(Insert Table 5 about here)

Considering this result, the TVECM 3 could be re-specified as a Band-TVECM as has been defined in Section 3. A Wald test is carried out to check if the adjustment coefficients in the middle regime are jointly significant in both systems. Results indicate that, in both systems, the null of no significance cannot be rejected at the 5\% significance level (the Wald statistic is 3.25 and 4.54 for systems FP-PP and PP-RP, 
respectively, while the critical value is 5.99). Consequently, it can be concluded that Band-TVECM is more appropriate than the unrestricted TVECM to represent the asymmetric adjustments of poultry prices in the marketing channel. The first regime is associated with lower marketing margins while the third regime corresponds to periods with higher marketing margins in both systems.

The estimated parameters of the Band-TVECM for the two systems are given in Table 6. Furthermore, we include the estimates of the adjustment parameters $\hat{\rho}_{i}$, which measure how the cointegrating vector reverts to the regime-specific mean (see footnote 3). As can be observed, the estimated parameters $\hat{\rho}_{i}$ in regime 1 are always lower than those in the upper regime. A smaller $\hat{\rho}_{i}$ means that price adjustments after disequilibria are faster. In the lower regime $\rho$ is 0.403 for system (FP-PP) and 0.447 for system (PPRP) and increases to 0.773 and 0.48 for systems one and two, respectively. In other words, adjustments are faster when deviations from the long-run equilibrium are negative.

\section{(Insert Table 6 about here)}

The speed of adjustment is usually measured by the so-called half-life $\left[\ln (0.5) / \ln \left(\hat{\rho}_{i}\right)\right]$ which states the number of periods required to reduce one-half of a deviation from the long-run equilibrium (Taylor, 2001). Taking into account the results mentioned in the above paragraph, the half-life increases from 0.76 and 0.85 weeks to 2.69 and 0.94 weeks for system (FP-PP) and system (PP-RP), respectively. These results indicate that the adjustment induced by a negative deviation from the stationary price relationship is much faster than when it is induced by a positive deviation.

In any case, as we have already mentioned in the previous section, the key feature in threshold models is the pattern of the estimated coefficients of the $\alpha$ matrix $\left(\alpha_{\mathrm{ij}}\right)$ associated with the cointegrating vector in each regime. These coefficients can be useful to analyse which prices "equilibrium adjust" and which do not. Although these results will be better understood by computing the impulse response functions, which will be the aim of the next section, we will try to anticipate some of these results here.

In the PP-RP subsystem, after a positive deviation from the long-run equilibrium (third regime), adjustment coefficients are significant, indicating a feedback effect between the two prices. In addition, estimated coefficients indicate that the speed of 
adjustment of the retail prices is slower than that of the producer prices (the retail price adjusts by eliminating $14 \%$ of the positive impact generated in the previous period, while in the case of the producer price the adjustment is $35 \%$ ). In the case of a negative deviation, this situation is reinforced as retail prices do not adjust to changes in the long-run equilibrium. These results indicate, consistent with previous literature, that retail prices are sticky relative to producer prices.

In the (FP-PP) system, the results are fairly representative of vertically integrated markets. Positive shocks to the price spread generate a quicker adjustment of feed prices while they remain more rigid after negative shocks to the price spread. Thus, in both cases there is a quick adjustment to the long-run price spread equilibrium.

\subsection{Short-Run Dynamics}

Short-run dynamics have been analysed by computing the IRF, which show the response of each price in the system to a shock in any other price. In this study, nonlinear IRF (NIRF) have been calculated for both of the system for regimes 1 and 3. In a context of non-linear models, NIRF are very useful tools, as they allow us to differentiate responses to both positive and negative shocks. Moreover, the time at which the shock takes place is relevant and, thus, we could expect different responses depending on which of the regimes the shock is produced in.

In order to analyse the asymmetric behaviour of price adjustments, the NIRF have been computed for $\delta= \pm 1$ and for history-specific regimes in which the long-run equilibrium relationship ( $\mathrm{i}=1,2$ for the first and second system, respectively) is above or below the upper and lower threshold values. Figures 2 and 3 show the NIRF for each system. In each regime, the NIRF for each forecasting horizon is the average across all possible $\mathrm{N}_{\mathrm{i}}$ histories (with $\mathrm{N}_{\mathrm{i}}$ being the number of observations in the $\mathrm{i}^{\text {th }}$ regime).

Figure 2 shows the NIRF for the system (FP-PP) to $1 \%$ positive and negative shocks produced in both the first and the third regimes. Several implications for price relationships arise from it. As can be observed, responses to a shock in feed prices generate symmetric responses, that is, the effects of positive and negative shocks are more or less of the same magnitude. This symmetric behaviour is quite consistent with previous expectations as these two levels of the marketing chain are vertically integrated. Moreover, responses are similar in the two regimes. On the other hand, 
producer prices are more flexible than feed prices in the short-run, increasing producer marketing margins as a consequence of cost-pushes.

(Insert Figure 2 about here)

A shock to the producer price does not generate any response in feed prices in either of the two regimes. This result clearly indicates the existence of a cost-push price transmission mechanism in the FP-PP system. Responses of producer prices are more persistent. An interesting result here in relation to the responses of producer prices is that, in the first regime (negative deviation from the long-run price spread), price adjustment is positive-asymmetric, that is, price increases are transmitted faster than price decreases. However, in the other regime (positive deviation from the long run price spread) the opposite occurs. These results indicate that in the Spanish poultry sector prices react quickly to changing conditions to reach long-run equilibrium immediately.

Let us now consider the system (PP-RP) under the first regime, i.e. negative deviation to the long-run price spread equilibrium (Figure 3). In general terms, responses are fairly symmetric. A positive shock to the producer price squeezes the marketing margin. On the other hand, negative shocks generate increasing price spreads. This result shows a fairly competitive behaviour. This is not surprising, given the degree of vertical integration which makes firms work with cost functions characterised by increasing returns to scale. Under such circumstances, McCorriston et al., (2001) showed that the retailing market power could be offset. This situation is radically different to that existing in other meat markets, in which production is not so highly vertically and horizontally concentrated. Moreover, $1 \%$ positive or negative shocks to the retail price generate responses of lower magnitude than in the producer price, indicating, also at this level of the marketing chain, a cost-push transmission mechanism.

(Insert Figure 3 about here)

The situation changes in some way in the third regime, characterized by positive deviations of the long-run producer-retailer price spread. The price transmission mechanism holds, as responses to a shock in the producer price are of higher magnitude than in the case of a shock in the retail price. As can be observed in Figure 3, a positive shock in the producer price generates immediate responses of both prices of the same 
magnitude keeping marketing margins constant. However, responses to negative shocks are very low, suggesting that positive shocks are more persistent and generate positive asymmetries.

A $1 \%$ positive shock to the retail price generates an immediate and significant response of both prices. However, the magnitude of such responses is quite different. The wholesale price exhibits a certain delay in adjusting to the new situation, reaching the maximum response after three weeks. Thus, although in the long run both prices are homogeneous, in the very short-run retailers benefit from a demand shock as the price spread increases. In the case of a negative shock to the retail price, price spreads also increases and producer prices show more nominal price flexibility. As can be easily observed, under positive deviations from long-run price spreads, the magnitude of the asymmetric effect is greater in the case of the retail price, suggesting that inflation in poultry products is not exclusively generated by cost increases, but rather by a mixture of both cost and marketing margin increases.

\section{Conclusions}

This paper has explored the non-linearity in the price transmission mechanism in the Spanish poultry marketing chain, a sector characterized by a high degree of vertical integration and horizontal concentration. Two sub-systems have been studied: on one hand, the relationship between farm and feed prices and, on the other, the price relationship between the producer and the retail market levels. The methodology used has been based on the specification and estimation of a three-regime TVECM. In both systems, price reactions in the intermediate regime are not significant, allowing us to specify a Band-TVECM. The results obtained suggest a number of points.

In the long run, prices at different levels of the marketing chain are perfectly integrated, that is to say, any change in any of the prices is fully transmitted to the rest. However, in the short run, results are different depending on the system being analysed. Price adjustments between the farm and the feed levels are quite consistent with the existence of intensive vertical coordination between these two steps of the Spanish poultry marketing chain. Reactions of both prices to positive and negative shocks are symmetric and producer prices are more flexible witch suggests that there is a cost-push transmission mechanism. 
The analysis of the price transmission mechanism between the producer and the retail levels offers a different picture and also depends on the specific regime in which the shock is generated. The main conclusion is that, in an environment of positive deviations from the long-run price spread, retailers benefit from any shock, whether positive or negative, that affects supply or demand conditions. In the first regime (negative deviations from long-run equilibrium), marketing margins tend to remain quite stabilised.

The analysis has focused on vertical price adjustments in the Spanish poultry sector but it can be extended in several directions. First, a natural extension will be to investigate other meat sectors in Spain with different market structures (different degrees of market integration) or other food sectors with different characteristics (branded products, more processed products, non-perishable products, etc). From the methodological point of view further refinements could be used in the future as new theoretical econometric issues arise in the context of non-linear models in a multivariate framework.

\section{References}

AZZAM, A. (1999) “Asymmetry and Rigidity in Farm-Retail price Transmission”. American Journal of Agricultural Economics, 81, 525-533.

BAILEY, D.V. and BRORSEN, B.W. (1989): "Price Asymmetric in Spatial Fed Cattle Markets." Western Journal of Agricultural Economics, 14: 246-252.

BALKE, N.S. and FOMBY, T.S. (1997): "Threshold Cointegration." International Economic Review, 38: 627-645.

BANERJEE, A., LUMSDAINE, R.L. and STOCK, J.H. (1992): "Recursive and sequential test of the unit root and trend-break hypotheses: theory and international evidence". Journal of Business and Economic Statistics, 10: 271-287.

BETTENDORF, L. and F. VERBOVEN (2000): "Incomplete Transmission of Coffee Bean Prices: Evidence from the Dutch Coffee market". European Review of Agricultural Economics, 27, 1-16.

BLINDER, A.S., CANETTI, E.R., LEBOW, D.E. and RUDD, J.B. (1998): “Asking about Prices: A new Approach to Understanding Price Stickiness", Russel Sage Foundation, New York

BORENSTEIN, S., CAMERON, A.C. and GILBERT, R. (1997): "Do Gasoline Prices respond asymmetrically to Crude Oil Price Changes?". Quarterly Journal of Economics, 112: 305-339

BOYD, M.S. and BRORSEN, B.W. (1988): "Price Asymmetry in the U.S. Pork Marketing Channel." North Central Journal of Agricultural Economics, 10: 103-109.

BUCKLE, R.A. and CARLSON, J.A. (2000): "Inflation and asymmetric Price Adjustment". Review of Economics and Statistics, 82(1): 157-160

CHAVAS, J.P. and MEHTE, A. (2002): "Price dynamics in a vertical sector: the case of butter". Agricultural and Applied Economics Staff Paper Series, 452. University of WisconsinMadison. 
DOORNIK, J.A. and HENDRY, D.F. (1997): "Modelling Dynamic systems using PcFilm 9 for Windows". Timberlake Consulting, London.

ENGLE, R.F. and GRANGER, C.W.J. (1987). "Co-integration and Error Correction: Representation, Estimation and Testing". Econometrica 55: 251-276.

ESCRIBANO, A. and MIRA, S. (1996): "Nonlinear cointegration and nonlinear errorcorrection models". Working paper, Universidad Carlos III de Madrid.

FRANSES, P.H. (1991): "Model selection and seasonality in time series". Tinbergen Institute series $n^{\circ} 18$. Erasmos University. Roterdam.

FRANSES, P.H. and VAN DIJK, D. (2000): "Non-linear Time Series Models in Empirical Finance." Cambridge University Press.

GOODWIN, B. K. and HOLT, M. T. (1999): "Price Transmission and Asymmetric Adjustment in the U.S. Sector." American Journal of Agricultural Economics, 81(3): 630-637.

GOODWIN, B.K. and PIGGOTT, N.E. (2001): "Spatial Market Integration in the Presence of Threshold Effects". American Journal of Agricultural Economics, 83(2): 302-317

GRIFFITH, G.R. and PIGGOT, N.E. (1994): "Asymmetry in Beef, Lamb and Pork Farm-Retail Price Transmission in Australia". Agricultural Economics, 10: 307-316

GRANGER, C.W.J. and LEE, T.H. (1989): "Investigation of Production, Sales and Inventory Relationships using Multicointegration and Non-Symmetric Error Correction Models". Journal of Applied Econometrics, 2: 111-120.

HAHN, W.F. (1990): “ Price Transmission Asymmetry in Pork and Beef Markets.” Journal of Agricultural Economics, 42: 102-109.

HANSEN, B.E. (1997): "Inference in TAR Models." Studies in Nonlinear Dynamics and Econometrics, 2: 1-14.

HANSEN, B.E. (1999): “Testing for linearity. Journal of Economic Surveys, 13:551-576.

HANSEN, B.E. and SEO, B. (2001): "Testing for Two-Regime Threshold Cointegration in Vector Error Correction Models". Journal of Econometrics, forthcoming.

HANSMIRE, M.R, and WILLETT, L.S. (1992): "Price Transmission Processes: A Study of Price Lags and Asymmetric Price Response Behaviour for New York Red Delicicious and McIntosh Apples." Cornell, N.Y., Cornell University.

HOUCK, J.P. (1977): "An Approach to Specifying and Estimating Nonreversible Functions." American Journal of Agricultural Economics, 59: 570-572.

JOHANSEN, S. (1988): "Statistical Analysis of the Cointegration Vectors". Journal of Economic Dynamics and Control, 12: 231-254.

JOHANSEN, S. (1995): "Likelihood-based Inference in Cointegrated Vector Autoregressive Models." Oxford University Press, Oxford.

JOHANSEN, S. and JUSELIUS, K. (1994): "Identification of the Long-Run and the Short-Run Structure: An Application to the ISLM Model." Journal of Econometrics, 63: 7-36.

JOHANSEN, S., MOSCONI, R. and NIRLSEN, B. (2000): "Cointegration analysis in the presence of structural breaks in deterministic trend". Econometrics Journal, 3:216-249.

KINNUCAN, H.W. and FORKER, O.D. (1987): "Asymmetry in the Farm-Retail Price Transmission for Major Dairy Products." American Journal of Agricultural Economics, 69: 285-292.

KOOP, G., PESARAN, M.H. and POTTER, S.M. (1996): "Impulse Response Analysis in Nonlinear Multivariate Models." Journal of Econometrics, 74: 119-147.

LAWRENCE, J.D., RHODES, V.J., GRIMES, G.A. and HAYENGA, M.L. (1997): "Vertical Coordination in the US Pork Industry: Status, Motivations, and Expectations". Agribusiness, 13(1):21-31.

LO, C. and ZIVOT, E. (2001): "Threshold Cointegration and Nonlinear Adjustments to the Law of One Price". Macroeconomic Dynamics, 5: 533-576.

McCORRISTON, S., MORGAN, C. W. and RAYNER A. J. (2001): "Price Transmission: The Interaction Between Market Power and Returns to Scale". European Review of Agricultural Economics, 28: 143-159. 
PELTZMAN, S. (2000): "Prices Rise Faster than they fall". Journal of Political Economy, 108(3): 466-502

PERRON, P. (1989): "The Crash, the Oils shock and the Unit Root Hypothesis". Econometrica, 57: 1361-1402.

POTTER, S.M. (1995): “A Nonlinear Approach to U.S. GNP.” Journal of Applied Economics, 10: $109-125$.

RAPPOPORT, P. and REICHLIN, L. (1990): "Segmented trend and nonstationary time series". The Economic Journal, 99: 168-177.

REAGAN, P.B. and WEITZMAN, M.L. (1982): "Asymmetries in Price and Quantity Adjustments by the competitive Firm". Journal of Economic Theory, 27: 410-420

TAYLOR, A.M. (2001): "Potential pitfalls for the Purchasing-power-Parity puzzle? Sampling and specification bias in mean-reversion tests of the low of one price". Econometrica, 69:473-498.

TIAO, G.C. and BOX, G.E. (1981): "Modeling Multiple Time Series Applications." Journal of American Statistical Association, 76: 802-816.

TIFFIN, R. and DAWSON, P.J. (2000). " Structural Break, Cointegration and the Farm-Retail Price Spread for Lamb”. Applied Economics, 32: 1281-1286.

TSAY, R. (1998): "Testing and modelling multivariate threshold models". Journal of the American Statistical Association, 93(1):1188-1202.

VAN DIJK, D. and FRANSES, P.H. (1997): "Nonlinear error-correction models for interest rates in the Netherlands". Working paper, Tinbergen Institute, Erasmus University Rotterdam.

VON CRAMON-TAUBADEL, S. (1998). Estimating asymmetric price transmission with the error correction representation: An application to the German pork market. European Review of Agricultural Economics, 25: 1-18.

WARD, R.W. (1982): "Asymmetry in Retail, Wholesale and Shipping Point Pricing for Fresh Vegetable." American Journal of Agricultural Economics, 64: 205-212.

WOLFFRAM, R. (1971): "Positivistic Measures of Aggregate Supply Elasticities: Some New Approaches - Some Critical Notes." American Journal of Agricultural Economics, 53: 356-359. 
Table 1. Results from seasonal unit roots

\begin{tabular}{lcccccc}
\hline & \multicolumn{2}{c}{$\mathrm{FP}$} & \multicolumn{2}{c}{$\mathrm{PP}$} & \multicolumn{2}{c}{$\mathrm{RP}$} \\
\hline $\mathrm{H}_{0}: \pi_{\mathrm{i}}=0^{\mathrm{a}}$ & $\mathrm{A}^{\mathrm{b}, \mathrm{c}}$ & $\mathrm{B}^{\mathrm{b}, \mathrm{c}}$ & $\mathrm{A}$ & $\mathrm{B}$ & $\mathrm{A}$ & $\mathrm{B}$ \\
\hline$\pi_{1}$ & $-2,90$ & $-2,95$ & $-2,40$ & $-2,41$ & $-2,50$ & $-2,37$ \\
$\pi_{2}$ & $-3,85^{*}$ & $-3,18^{*}$ & $-3,84^{*}$ & $-3,18^{*}$ & $-3,14^{*}$ & $-2,79^{*}$ \\
$\pi_{3} \cap \pi_{4}$ & $14,59^{*}$ & $10,36^{*}$ & $9,90^{*}$ & $6,71^{*}$ & $8,92^{*}$ & $6,81^{*}$ \\
$\pi_{5} \cap \pi_{6}$ & $12,01^{*}$ & $11,01^{*}$ & $17,82^{*}$ & $9,12^{*}$ & $20,32^{*}$ & $13,70^{*}$ \\
$\pi_{7} \cap \pi_{8}$ & $25,71^{*}$ & $22,01^{*}$ & $11,99^{*}$ & $6,04^{*}$ & $9,58^{*}$ & $4,19^{*}$ \\
$\pi_{9} \cap \pi_{10}$ & $15,65^{*}$ & $12,05^{*}$ & $12,36^{*}$ & $8,72^{*}$ & $14,69^{*}$ & $12,63^{*}$ \\
$\pi_{11} \cap \pi_{12}$ & $18,69^{*}$ & $13,44^{*}$ & $8,46^{*}$ & $4,82^{*}$ & $11,43^{*}$ & $7,04^{*}$ \\
$\pi_{3 . .} \cap . . \pi_{12}$ & $19,30^{*}$ & $16,43^{*}$ & $13,99^{*}$ & $7,64^{*}$ & $15,48^{*}$ & $9,88^{*}$ \\
\hline
\end{tabular}

a. $\pi_{1}$ tests for unit roots at the regular frequency while the rest test for seasonal unit roots (see Franses (1991) for a definition of the respective statistics)

b. Model A includes an intercept and 11 seasonal variables. Model B only includes an intercept.

c. An $*$ indicates that the null of non-stationarity $\left(\pi_{\mathrm{i}}=0\right)$ is rejected at the $5 \%$ level of significance. Critical values are in Franses (1991). 
Table 2. Results from unit root tests with structural breaks ${ }^{\mathrm{a}}$

\begin{tabular}{llcc}
\hline & Break point & Price series in levels & Price series in first differences \\
\hline & & Statistic & Statistic \\
\hline FP & 85_Dic & $-1,120$ & -9.410 \\
PP & 85_Nov & $-0,992$ & -12.938 \\
RP & 85_May & $-1,147$ & -18.417 \\
\hline
\end{tabular}

a The critical value at the $5 \%$ level of significance is -4.51 . 
Table 3. Results from cointegration rank tests, significance of deterministic components in the model and marketing margins

\begin{tabular}{|c|c|c|c|c|}
\hline & \multicolumn{2}{|c|}{ PP-RP } & \multicolumn{2}{|c|}{ FP-PP } \\
\hline $\begin{array}{l}\text { Cointegration rank } \\
\text { statistic }\end{array}$ & \multicolumn{2}{|c|}{$\begin{array}{cc}\mathrm{H}_{0}: \mathrm{r}=0 & \mathrm{H}_{0}: \mathrm{r}=1 \\
51.62 & 13.33 \\
(35.38) & (17.88)\end{array}$} & \multicolumn{2}{|c|}{$\begin{array}{ll}\mathrm{H}_{0}: \mathrm{r}=0 & \mathrm{H} 0: \mathrm{r}=1 \\
52.25 & 10.30 \\
(35.38) & (17.88)\end{array}$} \\
\hline $\mathrm{H}_{0}: \beta=(1,-1) \sim \chi^{2}(1)$ & \multicolumn{2}{|c|}{$(3.84)$} & \multicolumn{2}{|c|}{$\begin{array}{ll}(35.38) & (17.88) \\
(3.84) & \end{array}$} \\
\hline $\mathrm{H}_{0}: \phi_{1}=\phi_{2}=0 \sim \chi^{2}(2)$ & \multirow{2}{*}{\multicolumn{2}{|c|}{$\begin{array}{l}(5.99) \\
(5.99)\end{array}$}} & 0.434 & $\frac{(3.84)}{(5.99)}$ \\
\hline $\mathrm{H}_{0}: \mu_{1}=\mu_{2}=0 \sim \chi^{2}(2)$ & & & 11.70 & $(5.99)$ \\
\hline $\begin{array}{l}\text { Price difference mean } \\
\text { in each sub-sample }\end{array}$ & \multicolumn{2}{|l|}{$\begin{array}{c}80: 01-85: 12 \\
0.604\end{array}$} & \multicolumn{2}{|c|}{$\begin{array}{cc}80: 01-85: 12 & 86: 01-01: 12 \\
1.167 & 1.075 \\
\end{array}$} \\
\hline $\begin{array}{l}\text { Marketing margins in } \\
\text { each sub-sample }\end{array}$ & $\begin{array}{l}\mathrm{R} \\
80: 01-85: 12 \\
83 \% \mathrm{PP}\end{array}$ & $\begin{array}{l}1 \text { margin } \\
86: 01-01: 12 \\
121 \% \mathrm{PP} \\
\end{array}$ & $\begin{array}{r}\text { Farm } \\
80: 01-85: 12 \\
218 \% \mathrm{FP} \\
\end{array}$ & $\begin{array}{c}\text { nargin } \\
\text { 86:01-01:12 } \\
191 \% \mathrm{PP} \\
\end{array}$ \\
\hline
\end{tabular}

Note: Values in parentheses are critical values at the $5 \%$ level of significance 
Table 4. Tests for non-linearities in price adjustment in systems (FP-PP) and (PP-RP) ${ }^{\mathrm{a}, \mathrm{b}}$

\begin{tabular}{|l|c|c|c|c|}
\hline & \multicolumn{2}{|c|}{ FP-PP } & \multicolumn{2}{c|}{ PP-RP } \\
\hline & $\mathrm{LR}_{13}$ & $\mathrm{LR}_{23}$ & $\mathrm{LR}_{13}$ & $\mathrm{LR}_{23}$ \\
\hline Test statistic & 61.34 & 35.28 & 53.28 & 36.82 \\
\hline Critical value (5\%) & 43.54 & 32.65 & 48.39 & 33.45 \\
\hline Threshold parameters & \multicolumn{2}{|c|}{$\hat{\lambda}=(-0.048,0.042)$} & \multicolumn{2}{c|}{$\hat{\lambda}=(-0.058,0.007)$} \\
\hline
\end{tabular}

a The $\mathrm{LR}_{1,3}$ tests the null of linearity against the alternative of a TVECM (Lo and Zivot, 2001).

b The $\mathrm{LR}_{2,3}$ tests the null of a two-regime TVECM against the alternative of a three-regime TVECM (Lo and Zivot, 2001).

c Critical values are obtained using the parametric residual (PR) bootstrap algorithm (Hansen, 1999; and Hansen and Seo, 2001). 
Table 5. Estimated parameters of the $\mathrm{TVECM}_{3}$ for systems (FP-PP) and (PP-RP) ${ }^{\mathrm{a}}$

\begin{tabular}{|c|c|c|c|}
\hline \multicolumn{4}{|c|}{ System (FP-PP) } \\
\hline & $\begin{array}{c}\text { Regime } 1^{b} \\
\omega_{t-1}\left(\beta_{1}\right)<-0.048\end{array}$ & $\begin{array}{c}\text { Regime } 2^{b} \\
-0.048 \leq \omega_{t-1}\left(\beta_{1}\right) \leq 0.042\end{array}$ & $\begin{array}{c}\text { Regime } 3^{\mathrm{b}} \\
\omega_{\mathrm{t}-1}\left(\beta_{1}\right)>0.002\end{array}$ \\
\hline$\left(\begin{array}{l}\alpha_{1}^{\mathrm{i}} \\
\alpha_{2}^{\mathrm{i}}\end{array}\right)$ & $\left(\begin{array}{c}-0.58 \\
(0.115) \\
0.021 \\
(0.021)\end{array}\right)$ & $\left(\begin{array}{c}0.10 \\
(0.27) \\
-0.00 \\
(0.021)\end{array}\right)$ & $\left(\begin{array}{c}-0.11 \\
(0.034) \\
0.027 \\
(0.011)\end{array}\right)$ \\
\hline \multicolumn{4}{|c|}{ Misspecification tests } \\
\hline $\mathrm{BG}(1)-\mathrm{FP}^{\mathrm{d}}$ & 2.31 & BG(1)-PP & 3.29 \\
\hline $\mathrm{BG}(12)-\mathrm{FP}^{\mathrm{d}}$ & 2.73 & BG(12)-PP & 1.12 \\
\hline $\mathrm{ARCH}(1)-\mathrm{FP}^{\mathrm{e}}$ & 0.86 & ARCH(1)-PP & 0.84 \\
\hline $\mathrm{ARCH}(12)-\mathrm{FP}^{\mathrm{e}}$ & 2.86 & ARCH(12)-PP & 1.55 \\
\hline JB-FP ${ }^{f}$ & 3.77 & JB-PP & 4.52 \\
\hline$\%$ of observations & 30.63 & 23.40 & 45.95 \\
\hline \multicolumn{4}{|c|}{ System (PP-RP) } \\
\hline & $\begin{array}{c}\text { Regime } 1^{\mathrm{c}} \\
\omega_{\mathrm{t}-1}\left(\beta_{2}\right)<-0.058\end{array}$ & $\begin{array}{c}\text { Regime } 2^{\mathrm{c}} \\
-0.058 \leq \omega_{\mathrm{t}-1}\left(\beta_{2}\right) \leq 0.007\end{array}$ & $\begin{array}{c}\text { Regime } 3^{\mathrm{c}} \\
\omega_{\mathrm{t}-1}\left(\beta_{2}\right)>0.007\end{array}$ \\
\hline$\left(\begin{array}{l}\alpha_{1}^{i} \\
\alpha_{2}^{i}\end{array}\right)$ & $\left(\begin{array}{c}-0.047 \\
(0.12) \\
0.508 \\
(0.21)\end{array}\right)$ & $\left(\begin{array}{c}-0.302 \\
(0.27) \\
-0.253 \\
(0.38)\end{array}\right)$ & $\left(\begin{array}{c}-0.141 \\
(0.070) \\
0.353 \\
(0.150)\end{array}\right)$ \\
\hline \multicolumn{4}{|c|}{ Misspecification tests } \\
\hline $\mathrm{BG}(1)-\mathrm{PP}^{\mathrm{d}}$ & 0.28 & $\mathrm{BG}(1)-\mathrm{RP}$ & 0.55 \\
\hline $\mathrm{BG}(12)-\mathrm{PP}^{\mathrm{d}}$ & 2.58 & $\mathrm{BG}(12)-\mathrm{RP}$ & 2.23 \\
\hline ARCH(1)-PP & 1.69 & ARCH(1)-RP & 0.17 \\
\hline $\mathrm{ARCH}(12)-\mathrm{PP}^{\mathrm{e}}$ & 2.53 & $\mathrm{ARCH}(12)-\mathrm{RP}$ & 1.84 \\
\hline JB-FP ${ }^{f}$ & 6.02 & JB-WP & 5.47 \\
\hline$\%$ of observations & 22.55 & 31.48 & 45.95 \\
\hline
\end{tabular}

a Values in parentheses are standard deviations

b $\omega_{\mathrm{t}-1}\left(\hat{\beta}_{1}\right)=\mathrm{LnPP}-\mathrm{LnFP}-1.167 \mathrm{D}_{1 \mathrm{t}}-1.070 \mathrm{D}_{2 \mathrm{t}}$

c $\omega_{\mathrm{t}-1}\left(\hat{\beta}_{2}\right)=\mathrm{LnRP}-\mathrm{LnPP}-0.604 \mathrm{D}_{1 \mathrm{t}}-0.792 \mathrm{D}_{2 \mathrm{t}}$

d BG(i) is the Breush-Godfrey test for autocorrelation of order i (Critical value at the $5 \%$ level of significance is 3.84 )

e ARCH (i) is the Engle test for conditional heteroscedasticity of order i (Critical value at the 5\% level of significance is 3.84)

f JB is the Jarque-Bera test for normality. Critical value at the 5\% level of significance is 5.99 
Table 6. Estimated parameters of the Band-TVECM for systems (FP-PP) and (PP-RP)

\begin{tabular}{|c|c|c|c|c|c|c|}
\hline & \multicolumn{3}{|c|}{ Regime $1^{\mathrm{a}}$} & \multicolumn{3}{|c|}{ Regime $3^{\mathrm{a}}$} \\
\hline & $\left(\begin{array}{l}\alpha_{1}^{\mathrm{i}} \\
\alpha_{2}^{\mathrm{i}}\end{array}\right)$ & $\rho^{b}$ & Half-Life $^{c}$ & $\left(\begin{array}{l}\alpha_{1}^{\mathrm{i}} \\
\alpha_{2}^{\mathrm{i}}\end{array}\right)$ & $\rho^{b}$ & Half-Life \\
\hline FP-PP ${ }^{\mathrm{d}}$ & $\left(\begin{array}{c}-0.58 \\
(0.102) \\
0.017 \\
(0.021)\end{array}\right)$ & 0.403 & 0.76 & $\left(\begin{array}{c}-0.19) \\
(0.071) \\
0.037 \\
(0.009)\end{array}\right)$ & 0.773 & 2.69 \\
\hline PP-RP ${ }^{d}$ & $\left(\begin{array}{c}-0.047 \\
(0.12) \\
0.508 \\
(0.207)\end{array}\right.$ & 0.447 & 0.85 & $\left(\begin{array}{c}-0.14 \\
(0.071) \\
0.35 \\
(0.132)\end{array}\right)$ & 0.480 & 0.94 \\
\hline
\end{tabular}

a Regimes 1 and 3 have already been defined for both systems in Table 5.

b $\rho$ is the adjustment coefficient which measures how the cointegrating vector reverts to the regimespecific mean (see footnote 3 for its mathematical expression).

c Half Life is defined as $\left[\ln (0.5) / \ln \left(\rho_{i}\right)\right]$

d Values in parentheses are standard deviations 
Figure 1. Evolution of feed (FP), producer (PP) and retail (RP) price for poultry in Spain (Index, 1980=100) (1980-2000)

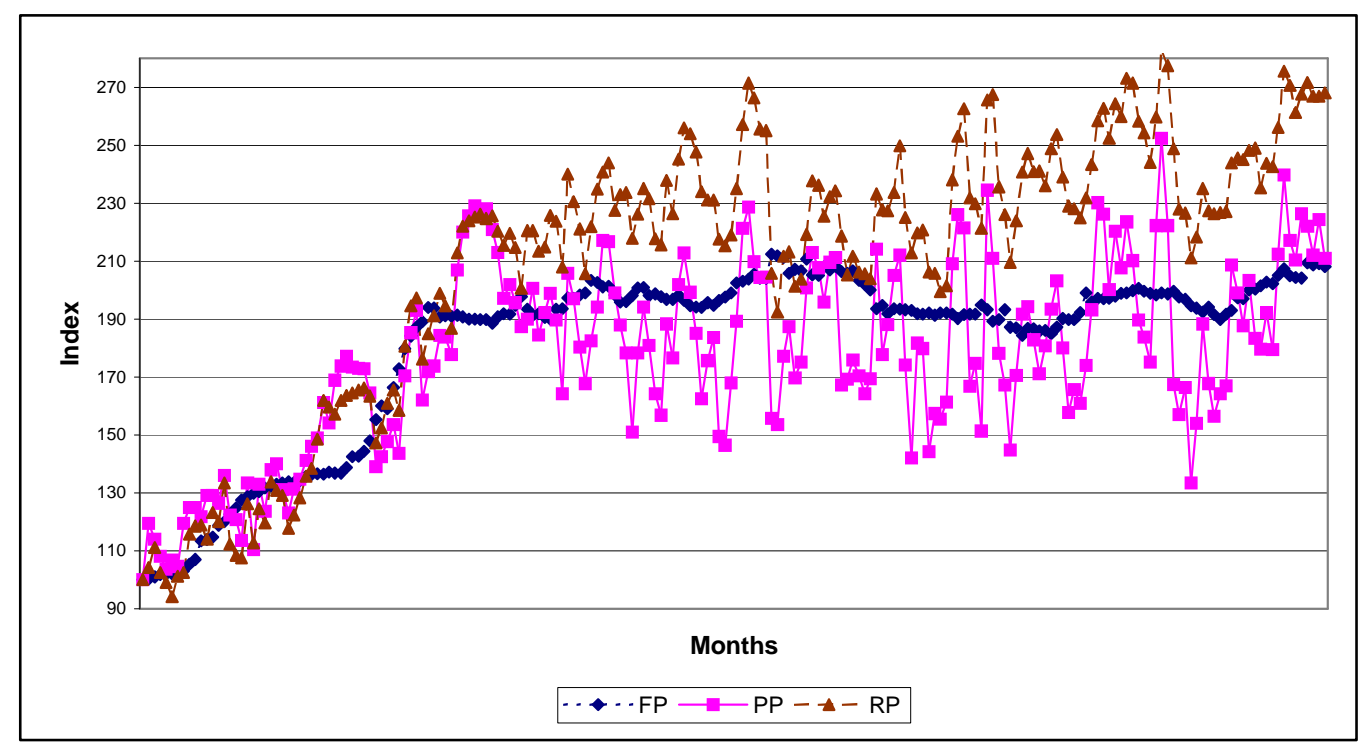

Source: MAPA, ICE and authors calculations 
Figure 2. Impulse response functions to a $1 \%$ positive and negative shock for system FP-PP under the two regimes

Regime $1\left(\omega_{t-1}\left(\beta_{1}\right)<-0.048\right)$
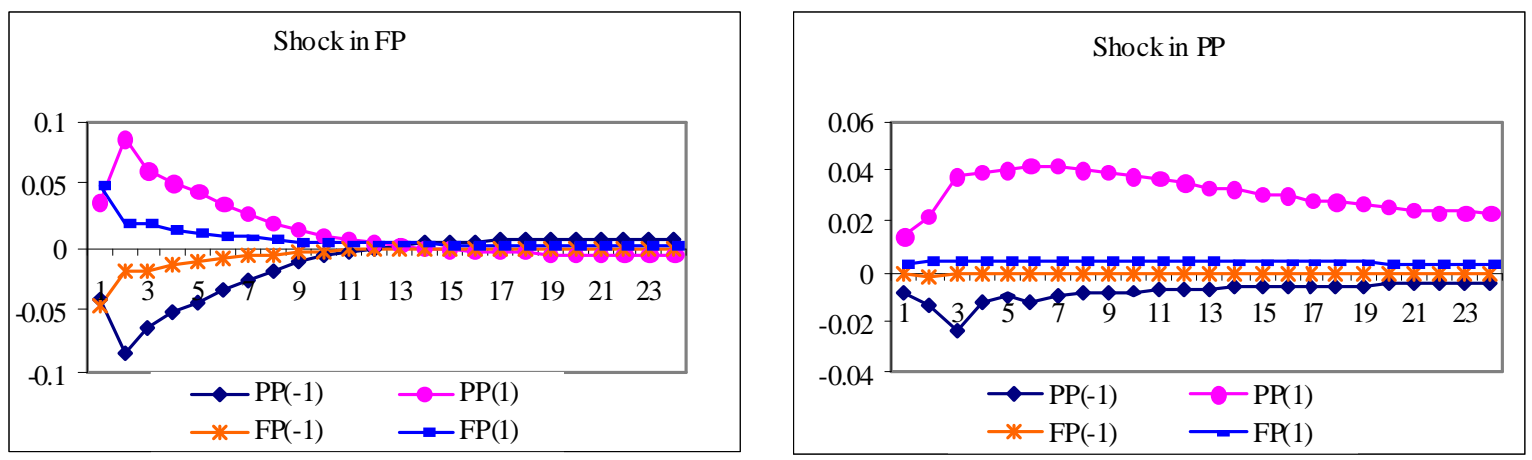

Regime $3\left(\omega_{\mathrm{t}-1}\left(\beta_{1}\right)>0.002\right)$
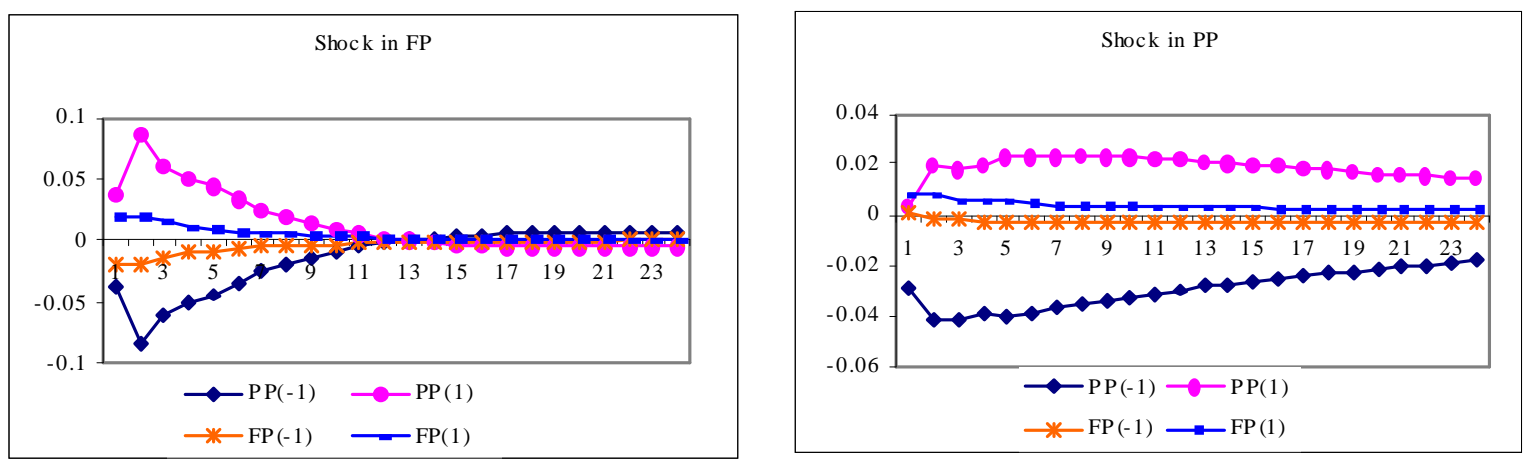
Figure 3. Impulse response functions to a $1 \%$ positive and negative shock for system PP-RP under the two regimes

Regime $1\left(\omega_{\mathrm{t}-1}\left(\beta_{2}\right)<-0.058\right)$
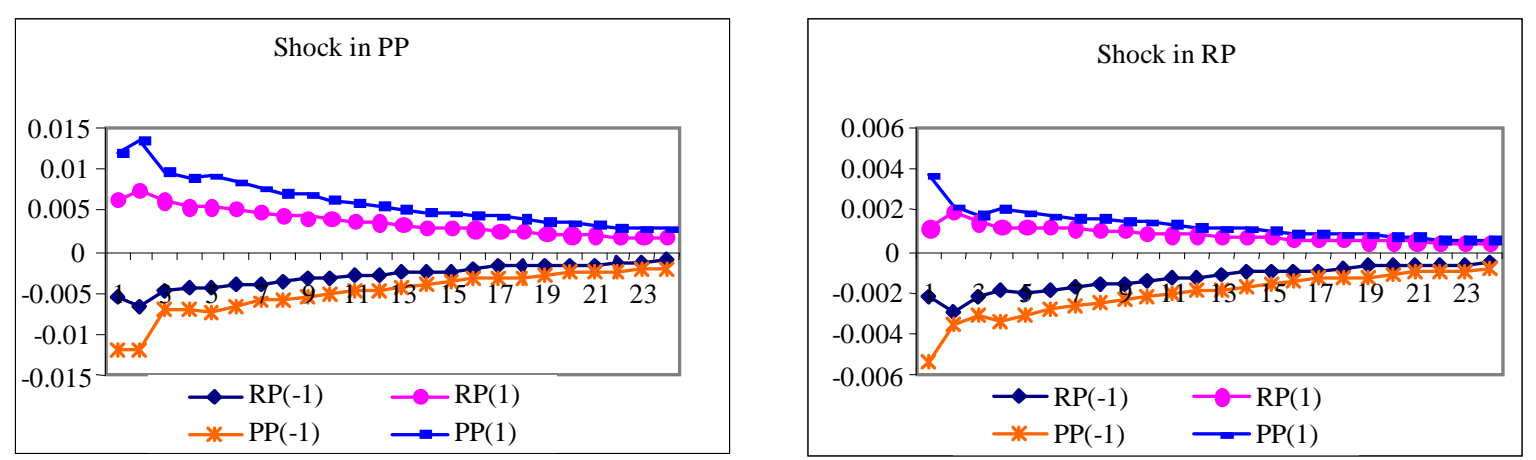

Regime $3\left(\omega_{t-1}\left(\beta_{2}\right)>0.007\right)$
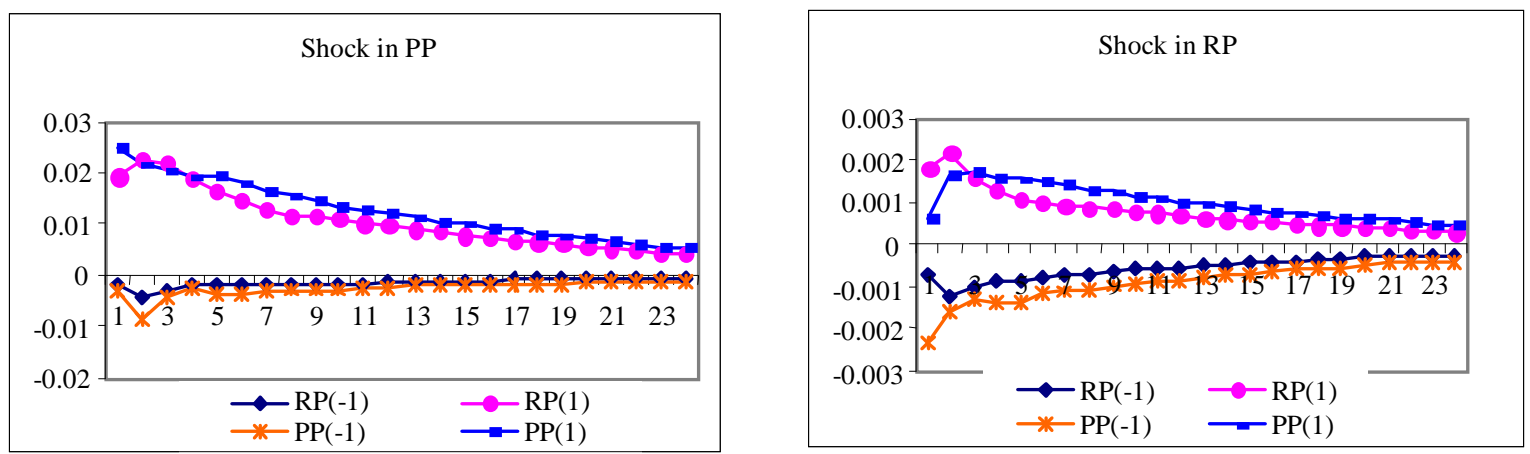